\title{
Effect of Pulmonary Blood Flow upon Lung Mechanics*
}

\author{
Stanley Giannelli, Jr.,市 Stephen M. Ayres, and M. E. Buehler with the \\ technical assistance of D. R. Armstrong and M. E. Stuart \\ (From the Departments of Surgery and Medicine, St. Vincent's Hospital and Medical Center \\ of New York and New York University School of Medicine, New York)
}

\begin{abstract}
Airway pressure was continuously recorded in an isolated horizontally mounted canine heart-lung preparation during abrupt, stepwise 100$200 \mathrm{ml}$ inflations to $20-25 \mathrm{~cm}$ water pressure, and subsequent deflations. With each change in volume there was a steep rise or fall in pressure, followed by stress relaxation to a static equilibrium airway pressure. Comparison was made between the nonperfused state and during perfusion with whole blood at $100 \mathrm{ml} / \mathrm{kg} \mathrm{dog}$ wt per min, and left atrial pressure of $10 \mathrm{~mm} \mathrm{Hg}$. Pressure tracings were similar during deflation in the perfused and the nonperfused lung. During inflation, in the middle range of lung inflation volumes, the peak inflation and equilibrium airway pressures were greater in the nonperfused state; maximum difference of static pressures in nine preparations averaged $146 \%$ of perfused values and the average stress relaxation difference from eight of these was $276 \%$. Lung distensibility was the same with packed red cells or plasma perfusates and was not changed by varying the perfusion rate up to $220 \mathrm{ml} / \mathrm{kg}$ per min. During cyclic ventilation, dynamic compliance was similarly greater in the perfused than in the nonperfused state in the middle range of inflation volumes. Static distention of the vascular bed produced similar results with progressive improvement in distensibility in midinflation range up to a hydrostatic pressure of $15 \mathrm{~cm}$ blood. These data suggest that the distended pulmonary vascular bed provides structural airway support which facilitates entry of gas into the terminal respiratory units at diminished pressure.
\end{abstract}

\section{Introduction}

The influence of the pulmonary vascular bed upon pulmonary mechanics is not clear. Basch, in 1887, suggested that perfusion of the pulmonary capillaries under normal conditions serves to maintain alveolar distention (1). Other investigators

* Received for publication 27 December 1966 and in revised form 15 June 1967.

This work was supported by the Health Research Council of the City of New York under contract No. $\mathrm{U}$ 1431, the National Institutes of Health, grants No. HE 08636 and No. HE 10781-01, and The Council for Tobacco Research-U.S.A.

This material was presented in part at the annual meeting of the American Federation for Clinical Research, Atlantic City, N. J., 1 May 1966.

$\ddagger$ Address requests for reprints to Dr. Stanley Giannelli, Jr., 153 West 11 Street, New York 10011. had reported that human cadaver lungs were less distensible than the lungs of living animals, and Basch inferred that the difference was due to a distending effect of capillary tension upon the alveoli in the latter.

There have been many subsequent reports relating lung distensibility to alterations of the pulmonary vasculature. Acute pulmonary congestion does not alter compliance (2), whereas chronic congestion is associated with decreased distensibility (3). Compliance is decreased in acute hemorrhagic shock when pulmonary blood flow is lowered (4). Borst et al., however, showed in a perfused canine lung preparation that compliance did not change over a wide range of blood flow (5). In patients with pulmonary overcirculation due to long standing intracardiac left-right shunts, 
lung compliance is decreased (6). The seemingly conflicting results in these reports are probably explained by associated lung parenchymal changes or metabolic alterations, and, therefore, changes in lung mechanics could not be related solely to changes in blood flow.

The proper starting point for developing an understanding of the relationship of pulmonary blood flow to compliance would seem to be the study of lung mechanics in normal lungs with and without pulmonary vascular perfusion. We are unaware that such data have been published. Static recoil pressure during deflation was measured by Frank in isolated animal lungs which were subjected to various levels of static, nonflowing vascular congestion up to $30 \mathrm{~cm}$ saline (7). Active perfusion was not performed, and the results suggested that filling of the pulmonary vascular bed did not have an important effect upon lung distensibility during deflation.

We have assessed the contribution of the vascular elements to pulmonary mechanics by studying an isolated, perfused, and ventilated canine heart-lung preparation. The data suggest that both the actively perfused and the statically distended vascular bed provide important structural support which facilitates the movement of gas into the terminal respiratory units at lower airway pressure.

\section{Methods}

The isolated, perfused, and ventilated heart-lung preparation is similar to that described by Donald (8). Mongrel dogs of both sexes and unknown ages were anesthetized with intravenous pentobarbital sodium. After receiving $2 \mathrm{mg}$ of heparin per $\mathrm{kg}$ intravenously, they were exsanguinated. The thorax was stripped of skin and shoulder girdle muscle, and the spinal column was divided between $\mathrm{T} 12-\mathrm{L} 1$, and through the middle cervical region. Other remaining soft tissues were divided and the thorax and its contents were thus isolated. At this point the trachea was cannulated with $\frac{1}{2}$ inch I.D., $\frac{3}{4}$ inch o.p. plastic tubing. This generally fit snugly, and was further secured with multiple wrappings of rubber bands. Ventilation was begun with humidified room air. A piston respirator with sine wave flow form was employed at a frequency of $20 / \mathrm{min}$. Peak airway inflation pressure was maintained at about $20 \mathrm{~mm} \mathrm{Hg}$, and expiratory pressure was regulated at about $5 \mathrm{~mm} \mathrm{Hg}$. All of the right costal cartilages were then divided and the rib cage was spread so that lung inflation did not displace the rib cage. The pulmonary artery and aorta were encircled with an umbilical tape, and a $\frac{1}{4}$ inch I.D. metal cannula was placed into the pulmonary artery from the right ventricle. The umbilical tape was tied, thus occluding the aorta and fixing the pulmonary arterial cannula. Each main coronary artery was ligated $2-3 \mathrm{~mm}$ from its origin with a silk suture. The mitral valve was excised through a $5-6 \mathrm{~cm}$ long left apical ventriculotomy and a $\frac{3}{8}$ inch I.D. metal cannula was inserted into the left ventricle so that its tip was positioned at the level of the excised mitral valve. The cannula was fixed in position by an umbilical tape around both ventricles. The ventriculotomy was further sealed off by sutures and the application of rubber cement around the cannula. Each of the vascular cannulae contained a central plastic catheter for pressure recording, which was led out the side of the plastic perfusion tubing connected to the cannulae. Airway pressure was measured at the tracheal cannula. Vascular and airway pressures were measured with Statham strain gauge transducers (Statham Instruments, Inc., Los Angeles, Calif.) and a multichannel electronic recorder. A metal rod was placed through the spinal canal, and the preparation was mounted horizontally upon a balance sensitive to $10 \mathrm{~g}$. Cyclic ventilation was continued with the piston pump throughout the duration of the experiment, except when measurements were being made. Just before measurements, the lungs were inflated several times to $30 \mathrm{~cm} \mathrm{H}_{2} \mathrm{O}$ airway pressure, and then were allowed to quickly deflate to atmospheric pressure. Measurements usually were begun $35-45 \mathrm{~min}$ after sacrifice of the animal.

The airway tubing was clamped, and the lungs were inflated every $30 \mathrm{sec}$ with sequential volumes of either 100 or $200 \mathrm{ml}$ of room air, and then deflation was carried out every $30 \mathrm{sec}$. We inflated the lung by hand, using maximum pressure, through a syringe via a length of plastic tubing inserted just proximal to the trachea. The entire pressure pattern during inflation and deflation was recorded. The airway pressures, before each additional inflation and deflation (equilibrium pressures), corresponded to points on a static compliance curve. These points were plotted on a vertical piece of paper attached to the side of the cathode tube, and the first series of inflations was stopped when the compliance curve began to rise steeply. Subsequent curves were obtained with the same number of inflations. Several inflation-deflation curves were obtained without perfusion, and then the vascular bed was perfused and similar airway pressure recordings were made.

In two preparations total lung gas was determined by the closed-circuit method when the lungs were allowed to collapse to the volume assumed at ambient pressure with and without pulmonary vascular perfusion. The perfused and nonperfused lungs were ventilated at an intermediate volume with $100 \%$ oxygen, maximally inflated, and then allowed to deflate to ambient pressure. The trachea was clamped and the lungs were flushed repeatedly with room air from an oiled, $200 \mathrm{ml}$ syringe. Pefore flushing, blood flow was stopped, and the venous line clamped so that venous pressure remained at $10 \mathrm{~mm}$ $\mathrm{Hg}$. This insured that minimal oxygen left the blood to equilibrate with the lowered oxygen tension of the mixture of gas from the lungs and the syringe. Tracheal 
gas was continuously sampled beginning $1 \mathrm{~min}$ after the onset of flushing and was analyzed by a nitrogen meter. The completeness of mixing was determined by directly reading the final nitrogen content from the instrument dial. The calculation of final nitrogen content was determined from the tracing fed into the recorder from the nitrogen meter.

Perfusion was accomplished by a rotary, double armed pump, which compressed the plastic perfusion tubing. Each complete revolution delivered $25 \mathrm{ml}$. In most experiments, the animal's own blood was the perfusate. In other experiments, heparinized plasma and packed red blood cell suspensions, obtained on the day of the experiment from several donors, were employed. At each flow rate, left atrial pressure was regulated by a constricting clamp on the perfusion line from left atrium to the reservoir, which was at floor level and to which blood drained by gravity.

During most perfusions the perfusate was maintained at $37^{\circ} \mathrm{C}$ by a heat exchanger placed in the perfusion line between the arterial pump and the preparation. In other experiments the perfusate was at room temperature. In several of the experiments, cyclic, sine wave changes in lung volume were induced at different rates by a piston respirator pump. The system was closed, so that air was actively withdrawn during expiration. These cyclic changes were imposed after different volumes of air were introduced into lungs that had been allowed to deflate to ambient pressure after several maximum inflations.

The effect of vascular bed distention without perfusion was studied in two preparations. Airway pressure data were obtained as described, first without pulmonary artery perfusion and next during perfusion at $100 \mathrm{ml} / \mathrm{min}$ per $\mathrm{kg}$ of dog weight, with left atrial pressure controlled at $10 \mathrm{~mm} \mathrm{Hg}$. Perfusion was then stopped and pulmonary artery and left atrial perfusion cannulae were clamped. Blood was added or withdrawn to achieve different levels of vascular bed pressure from 0 to 15 $\mathrm{mm} \mathrm{Hg}$ and stepwise inflation and deflation airway pressure data were obtained at different vascular pressures.

It was apparent that vascular distention without perfusion also improved lung distensibility, and, therefore, the preparation was modified in two experiments to evaluate this aspect. The thorax was prepared in the same manner except that the pulmonary arterial and left atrial cannulae were connected to graduated cylinders by flexible plastic tubing. These cylinders were filled with autogenous blood equilibrated with room air before measurements were begun. Equilibration was achieved by allowing the total blood volume of the cylinders to flow slowly by gravity several times from the arterial to the venous reservoir while the lungs were cyclically inflated. The pressure in the vascular system was controlled by adjusting both cylinders to the same height relative to the mid-left atrial level. Changes in blood volume in the lung were the reciprocal of these changes read directly from the cylinders when their levels were changed. Before recording volume changes from the graduated cylinder, we applied negative pressure to both arterial and venous cannulae by lowering the cylinders $10 \mathrm{~cm}$ below the left atrial level. This was assumed to empty the vascular bed although some blood undoubtedly remained both in the cardiac chambers and in the pulmonary vessels. After each set of measurements at a given vascular pressure, blood was again withdrawn from the lung and any discrepancy in 0 volume was assumed to represent edema fluid, and a correction was made in estimating the blood volume in the preparation at the next distending pressure. Airway pressure data were obtained in the manner already described.

During the course of our study, we found that it was possible to inflate the isolated lung with inflation patterns such that airway pressure fell during continued lung expansion. This phenomenon was more precisely documented to facilitate interpretation of the inflation-deflation curves obtained as described in the previous section. The heart-lung preparation was suspended in a 990 liter body plethysmograph and the trachea was connected to a tube led out from the box through a gas-tight port. One of the investigators repeatedly inflated the lungs by his own mouth pressure through the tracheal cannula. Different inflation patterns to near maximal expansion were produced. Airway and plethysmograph pressures were measured.

\section{Results}

This preparation is very difficult to work with. At flow rates of $100 \mathrm{ml} / \mathrm{kg}$ per min, with either homologous plasma or packed red cells, edema formation generally occurred within 15-30 min. A weight gain of up to $80-100 \mathrm{~g}$ in a $15-20 \mathrm{~kg}$ dog preparation would frequently occur before there was measurable decrease in compliance. Then inflation pressures would increase rapidly with further progressive weight gain. Tracheal foam was a late manifestation of pulmonary edema. Observations were stopped as soon as there was a weight gain and associated rises in inflation pressures. With autologous blood, perfusion at $100 \mathrm{ml} / \mathrm{kg}$ per min usually could be continued for 1-2 $\mathrm{hr}$ before the preparation gained weight. However, frequently a gradual decrease in compliance occurred before any weight gain, beginning 30-60 min after onset of perfusion. It could not be reversed by maximal inflations. We did not see this deterioration in the nonperfused lung during the repeated inflation curves performed before we obtained data with perfusion. This phenomenon has also been reported by Donald (9).

The tendency for deterioration of the preparation dictated the conduct of our study. It was not possible to evaluate all variables of perfusion in a single preparation. Air leaks were a major problem. In about $25 \%$ of experiments their 

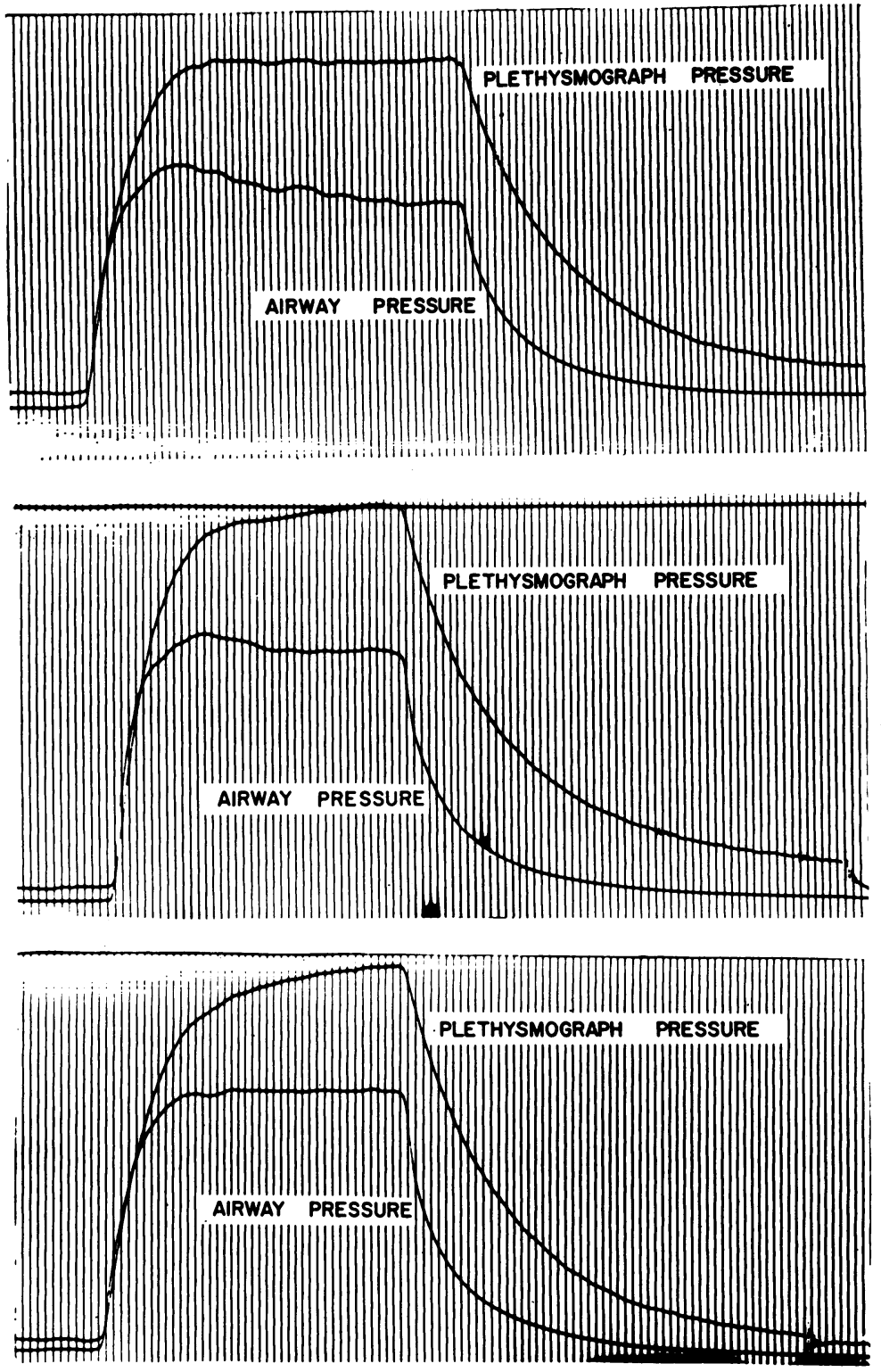

Fig. 1. Tracheal and plethysmograph pressures dURING LUNG inFLATION. The isolated thorax was suspended in a 990 liter body plethysmograph, and various inflation patterns were achieved by one of the investigators blowing into the tracheal cannula. Changes in lung volume and plethysmograph pressures were proportional. In the upper tracing, airway pressure fell while lung volume was constant, the usual representation of stress relaxation. In the middle tracing, airway pressure fell while lung volume was increasing. In the lower tracing, airway pressure was constant while lung volume increased. The break in the terminal portion of the plethysmographic pressure tracing, at end of expiration, represents venting of the box to atmospheric pressure. The near identity of pre- and postventing pressures shows that there had been no leak of gas from the lung. The time lines represent intervals of 1 sec. 
magnitude precluded obtaining any data. In some experiments, we observed slow leaks at the higher airway pressures. We did not consider them significant to the results, if airway pressure fell only 1 or $2 \mathrm{~cm}$ of water during $1 \mathrm{~min}$ at the highest level of lung inflation.

Fig. 1 presents three different patterns of expansion of canine lung that received direct inflation from the lungs of one of the investigators. Plethysmograph pressure increases in direct proportion to the lung volume. The breaks in the plethysmograph pressure tracing at the end of deflation are due to venting of the plethysmograph to the atmosphere. In the bottom tracing there is a negligible difference in plethysmograph pressure before and after venting. This indicates that there was no leak of gas from the lung to the plethysmograph. The greater plethysmograph pressure differences, after venting in the first two curves, are presumably due to a temperature rise in the plethysmograph. The upper tracing shows constant lung volume with decreasing airway pressure. The middle tracing represents simultaneously increasing lung volume and decreasing airway pressure. In the lower tracing, lung volume continues to increase while airway pressure is constant.

Fig. $2 a$ is the complete curve of lung inflation and deflation in the lung from a $13.6 \mathrm{~kg} \mathrm{dog}$, No. 8 of Table I. The upper tracing is without pulmonary vascular perfusion; the lower tracing is during pulmonary vascular perfusion at $100 \mathrm{ml} / \mathrm{kg}$ per min. Left atrial pressure was $10 \mathrm{~mm} \mathrm{Hg}$. $100-\mathrm{ml}$ volume changes were induced every $30 \mathrm{sec}$. There is a steep rise in airway pressure during the inflation period; then stress relaxation occurs, characterized by a fall in airway pressure with constant lung volume, until the next inflation. Stress relaxation also occurs during deflation, when the airway pressure gradually rises after an abrupt decrease in pressure.

Fig. $2 b$ is a convenient form of graphically depicting the airway pressure pattern which allows for comparison with other curves. The upper point for each line during inflation represents the peak inflation pressure from Fig. $2 a$, and the lower point corresponds to the static pressure after stress relaxation. At this time airway pressure had essentially stabilized, and the curve of these lower points describes a static compliance curve during inflation. We chose not to employ a longer interval between inflations so that airway pressure might further stabilize to a slight degree, because this would have lengthened the duration of perfusion, and consequently, deterioration of the preparation would have been a greater problem.

During deflation the lower point of each line represents the airway pressure immediately after removal of $100 \mathrm{ml}$ of air, and the upper point is the higher airway pressure after stress relaxation has occurred. These higher pressures describe the static compliance curve during deflation. A line connecting inflation and deflation equilibrium points inscribes a static hysteresis loop.

Lung volumes at ambient pressure were slightly higher in the perfused than in the nonperfused states in the two preparations studied by the closed-circuit method. In one study the gas contained in the lungs without perfusion measured $203 \mathrm{ml}$, and with perfusion, $245 \mathrm{ml}$. In the other preparation these values were $154 \mathrm{ml}$ and $176 \mathrm{ml}$, respectively.

There was always a difference between the airway pressures during stepwise inflation in the perfused and the nonperfused lung. Static inflation pressures were always lower for the same inflation volume in the perfused lung, except at the upper range of lung inflation, where the values were similar in the perfused and the nonperfused states. During inflation, stress relaxation pressures were also greater in the nonperfused than in the perfused lung. These differences were greater than the differences in static pressures at corresponding lung volumes. As with the static pressures, stress relaxation pressures were similar under both conditions at the higher levels of lung inflation. The greatest relative difference between static pressures in Fig. 2 occurred at $400 \mathrm{ml}$ of lung inflation $(29.4 \mathrm{ml} / \mathrm{kg})$, at which point the ratio of the static pressure in the nonperfused state to the static pressure during perfusion was 1.33 . The greatest relative difference in stress relaxation pressures occurred at $500 \mathrm{ml}$ of lung inflation $(36.8 \mathrm{ml} / \mathrm{kg})$, where the ratio of the nonperfusion stress relaxation pressure to that during perfusion was 3.10. During deflation the static and stress relaxation pressures were similar.

A total of nine such experiments were performed. The data are summarized in Table $I$. Each preparation was perfused at $100 \mathrm{ml} / \mathrm{kg}$ per 


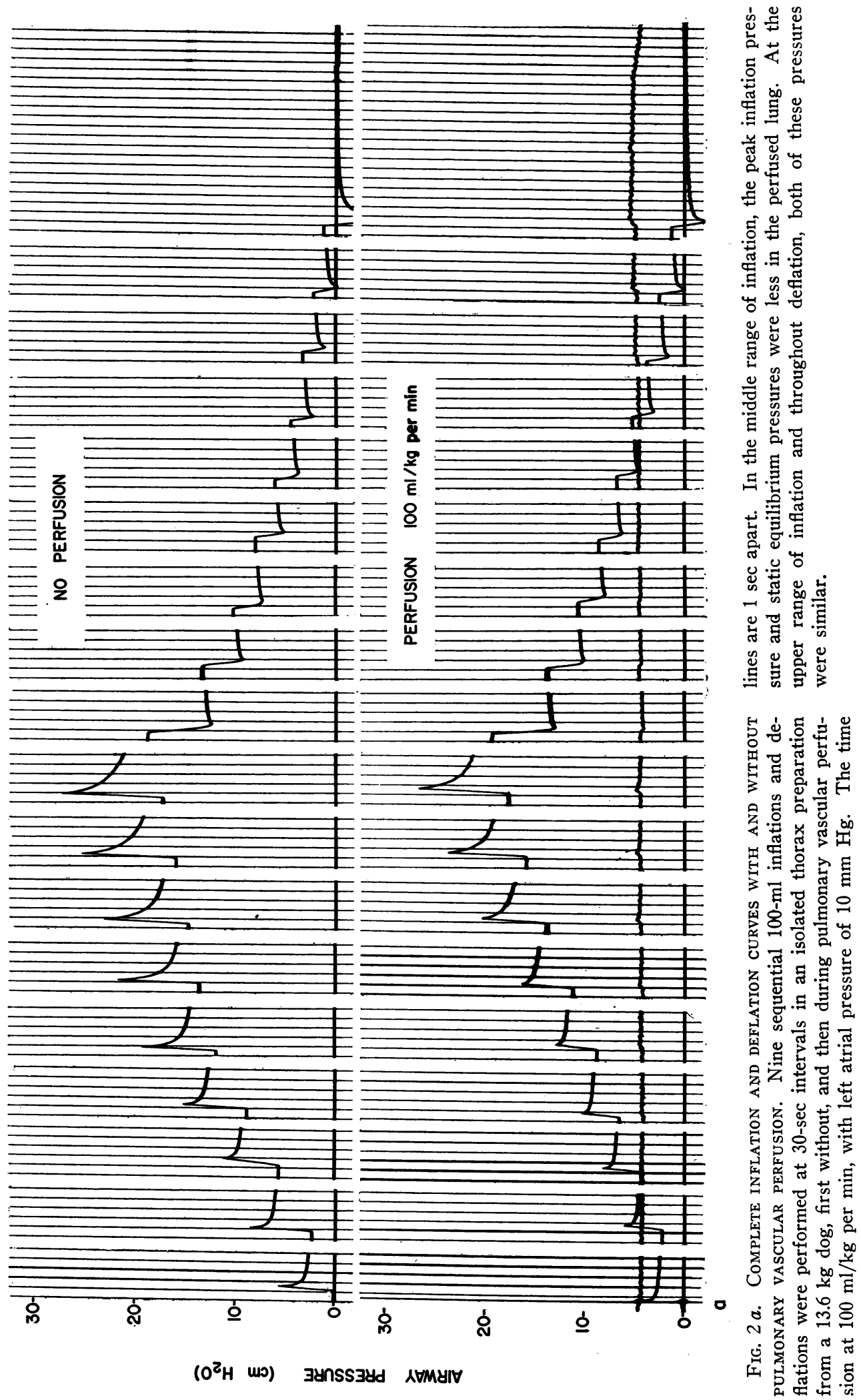




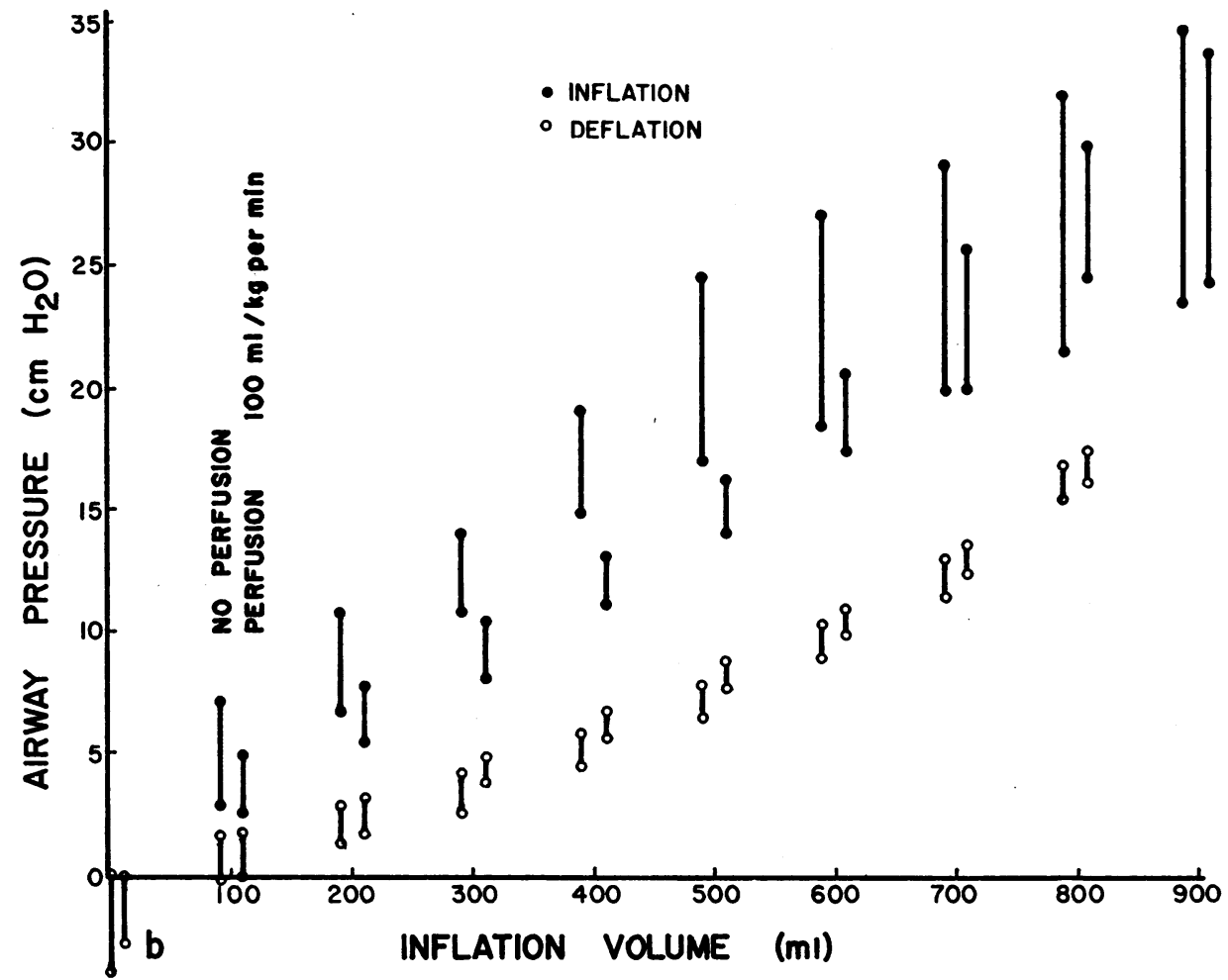

Fig. 2 b. Graphic presentation of data from Fig. 2 a. The upper point on each bar during inflation represents peak airway pressure; the lower dot is static equilibrium pressure before the next inflation. The length of the bar is the amount of stress relaxation. During deflation, airway pressure rises during stress relaxation, so that the lower point is the lowest deflation pressure, and the upper point of each bar is the static equilibrium pressure. A line connecting inflation and deflation equilibrium points inscribes a static hysteresis loop.

min and left atrial pressure was maintained at 10 $\mathrm{mm} \mathrm{Hg}$. The perfusate generally was autogenous blood; in several of the preparations, it was supplemented with up to several $100 \mathrm{ml}$ of blood from another dog. The net weight gain of the preparations never exceeded $60 \mathrm{~g}$ during the study, so that edema formation was negligible. The greatest differences in static and stress relaxation pressures for each study between the perfused and the nonperfused inflation are listed as the percentage by which the nonperfused values exceed the pressures during perfusion. The inflation volume at which these maximum differences occurred are listed as milliliters/kilogram body weight of the dog. The range of values for the ratios of static pressures was $1.22-2.00$, mean 1.46 ; the stress relaxation range was $1.75-4.67$, mean 2.76 . In dog 9 the tracheal pressure tracing was damped, so that relaxation data were incomplete.
In some of the studies, more than one curve was obtained under similar conditions, and these figures represent the averages of these curves. The reproducibility of results with repeated step-

TABLE I

Airway pressures during stepwise inflation in the perfused and nonperfused lung

\begin{tabular}{ccccc}
\multicolumn{5}{c}{ perfused and nonperfused lung } \\
\hline \hline Dog & $\begin{array}{c}\text { Static } \\
\text { pressure } \\
\text { ratio }\end{array}$ & & $\begin{array}{c}\text { Stress } \\
\text { relaxation } \\
\text { ratio }\end{array}$ & \\
\hline & & ml/kg & & ml/kg \\
1 & 1.22 & 21.93 & 1.75 & 8.77 \\
2 & 1.45 & 26.88 & 1.88 & 22.20 \\
3 & 1.65 & 20.00 & 2.88 & 45.00 \\
4 & 1.43 & 30.00 & 2.57 & 60.00 \\
5 & 1.30 & 23.53 & 2.57 & 47.06 \\
6 & 1.50 & 35.71 & 4.67 & 42.86 \\
7 & 1.29 & 17.00 & 2.63 & 31.50 \\
8 & 1.33 & 29.40 & 3.10 & 36.76 \\
9 & 2.00 & 45.40 & - & - \\
Mean & 1.46 & - & 2.76 & - \\
SD & 0.24 & - & 0.90 & - \\
\hline
\end{tabular}




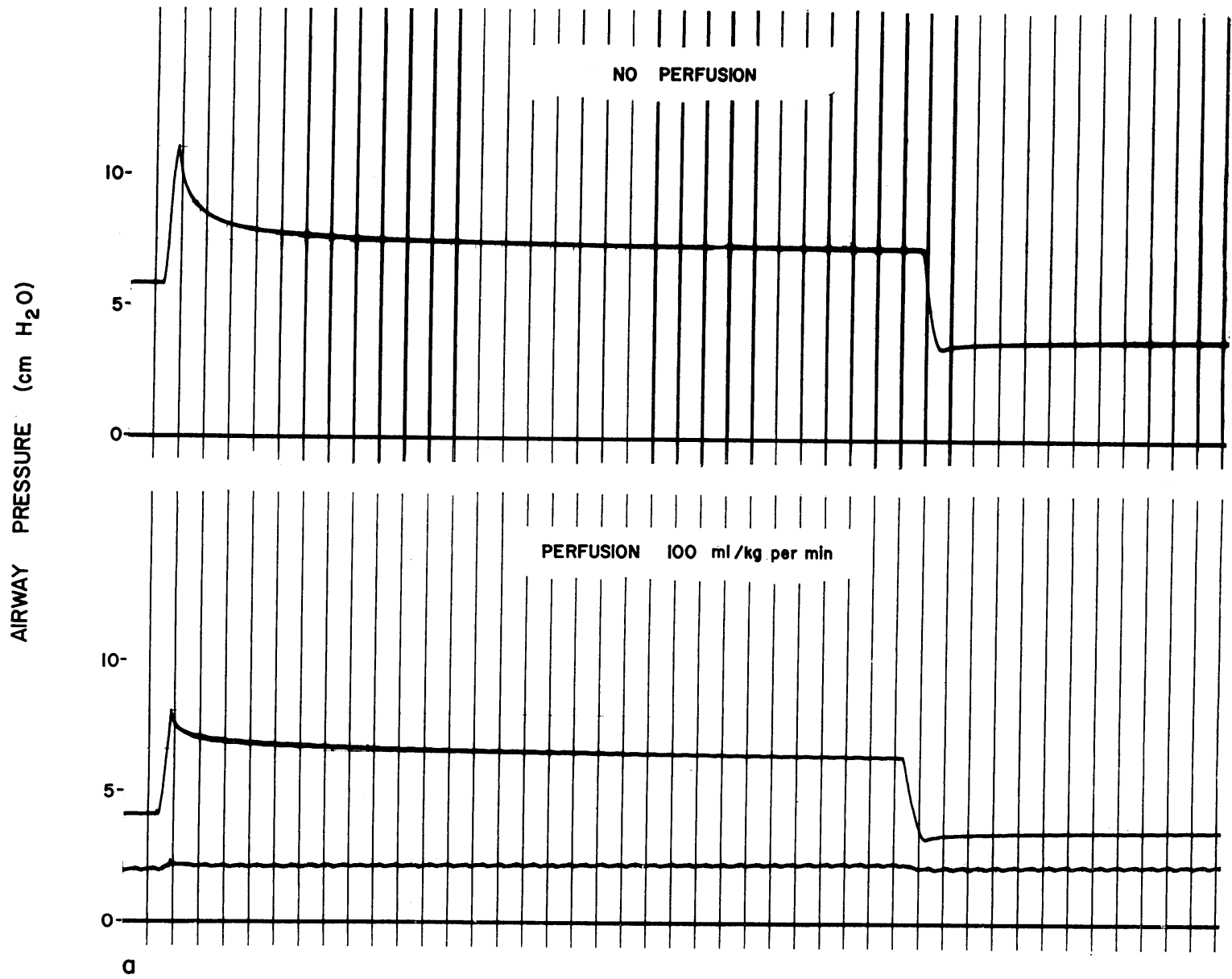

Fig. $3 a$. Stress Relaxation. The curves are expanded complete tracings of $200-\mathrm{ml}$ inflations in the perfused and nonperfused lung. $400 \mathrm{ml}$ had been introduced before these inflations. The time lines are at $1 \mathrm{sec}$ intervals. Perfusion rate was $100 \mathrm{ml} / \mathrm{kg}$ dog weight per min, and left atrial pressure was $10 \mathrm{~mm} \mathrm{Hg}$.

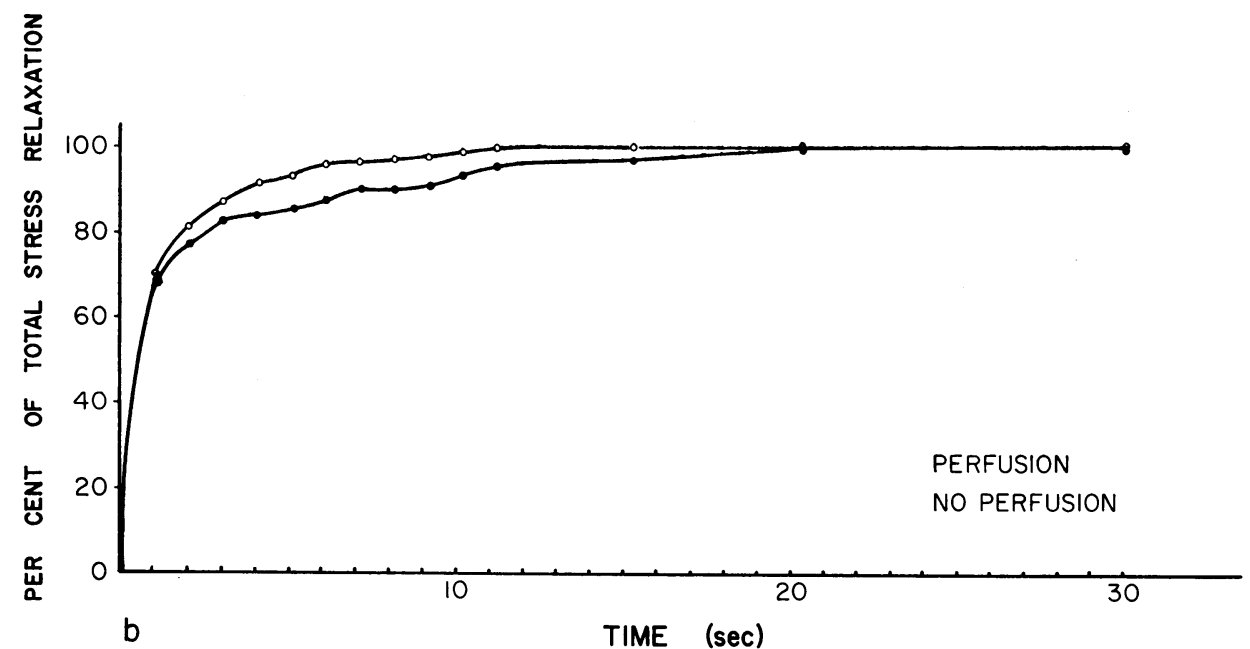

Fig. $3 b$. Percentage stress relaxation with time. Stress relaxation from Fig. $3 a$ is plotted for each curve as the percentage of total relaxation occurring with time. Closed circles indicate perfusion; open circles no perfusion. 


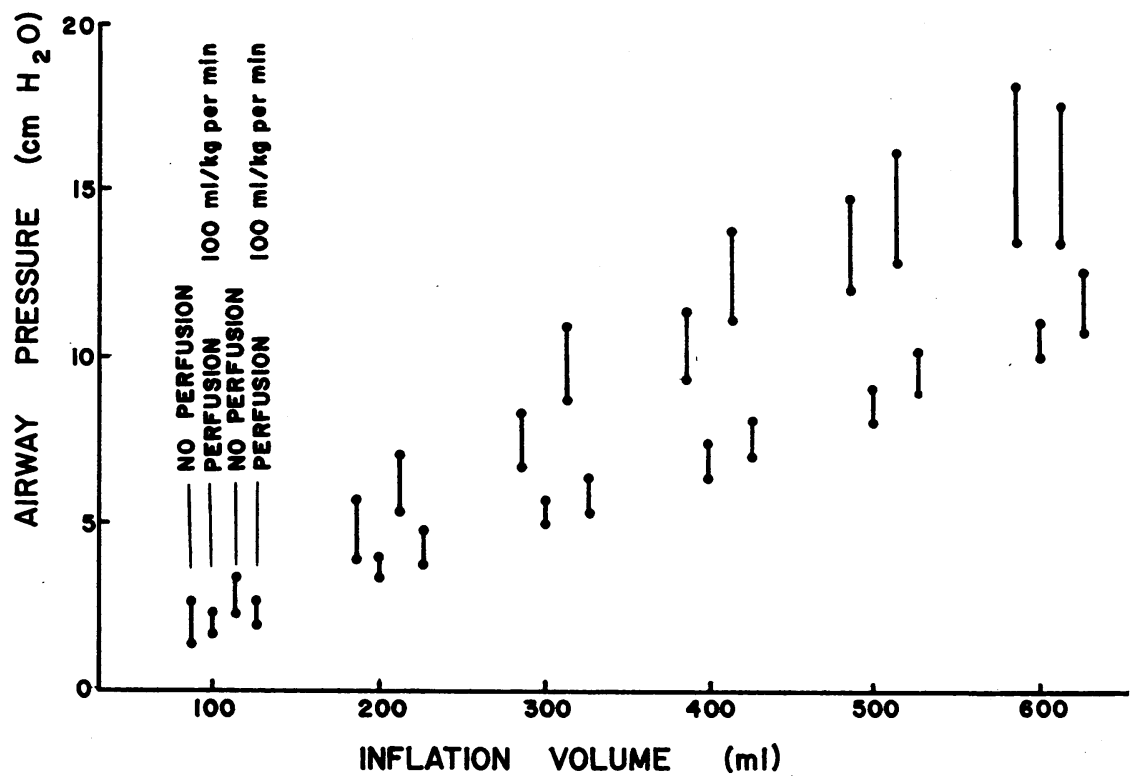

Fig. 4. REVERSIBILITY OF PERFUSION EFFECT UPON LUNG MECHANICS. Alternating inflation curves were obtained with and without pulmonary vascular perfusion. Only the inflation data are plotted.

wise inflations under similar conditions was good. There never was overlap of data from the perfused and nonperfused lungs in the middle range of inflation. Fig. $3 a$ represents two enlarged tracings from dog $8.400 \mathrm{ml}$ of air had been previously introduced into both lungs; after equilibration an additional $200 \mathrm{ml}$ of air was rapidly injected and $30 \mathrm{sec}$ later withdrawn. In Fig. $3 b$ the percentage of total relaxation is plotted each second.

Preparations 7, 8, and 9 were perfused with autogenous blood at room temperature, so that the airway pressure data were obtained at the same temperature with and without pulmonary vascular perfusion. The results were similar to those in the preceding experiments in which the lung was at room temperature when the data were obtained without perfusion, whereas the lung was at a higher temperature when being perfused with blood at $37^{\circ} \mathrm{C}$.

The changes in lung mechanics related to perfusion were readily reversible. Fig. 4 depicts inflation pressure curve data during alternately nonperfused and perfused states. Immediately after the initial measurements were made during perfusion at $100 \mathrm{ml} / \mathrm{kg}$ per min and left atrial pressure of $10 \mathrm{~mm} \mathrm{Hg}$, negative pressure was applied to the pulmonary arterial and the left atrial cannulae. The stress relaxation pressures and static compliance pressures rose and were similar to those during the initial nonperfused state. Then perfusion was quickly restarted and the inflation and static compliance pressures were similar to those during the initial period of perfusion. There was a general increase in pressures in the second set of data, which we interpreted to represent most probably deterioration of the preparation. This does not obscure the fact that the reversibility was readily achieved.

The degree of venous distention during perfusion, up to atrial pressure of $10 \mathrm{~mm} \mathrm{Hg}$, did not seem to influence lung mechanics. Fig. 5 represents successive inflation curves during perfusion at $100 \mathrm{ml} / \mathrm{kg}$ per min. The first set of airway pressures was obtained when atrial pressure was zero, achieved by the siphon effect on the left atrial cannula. Atrial pressure was then raised to $10 \mathrm{~mm} \mathrm{Hg}$ during the next inflation curve. The airway pressure data were similar during lung inflation at each atrial pressure. Mean pulmonary artery pressure was $28 \mathrm{~mm} \mathrm{Hg}$ during the first curve and $32 \mathrm{~mm} \mathrm{Hg}$ during the second.

The rate of perfusion, up to $220 \mathrm{ml} / \mathrm{kg}$ per min, did not affect airway pressures. Fig. 6 depicts successive inflation curves. Perfusion was 100 $\mathrm{ml} / \mathrm{kg}$ per min during the first perfusion inflation, 


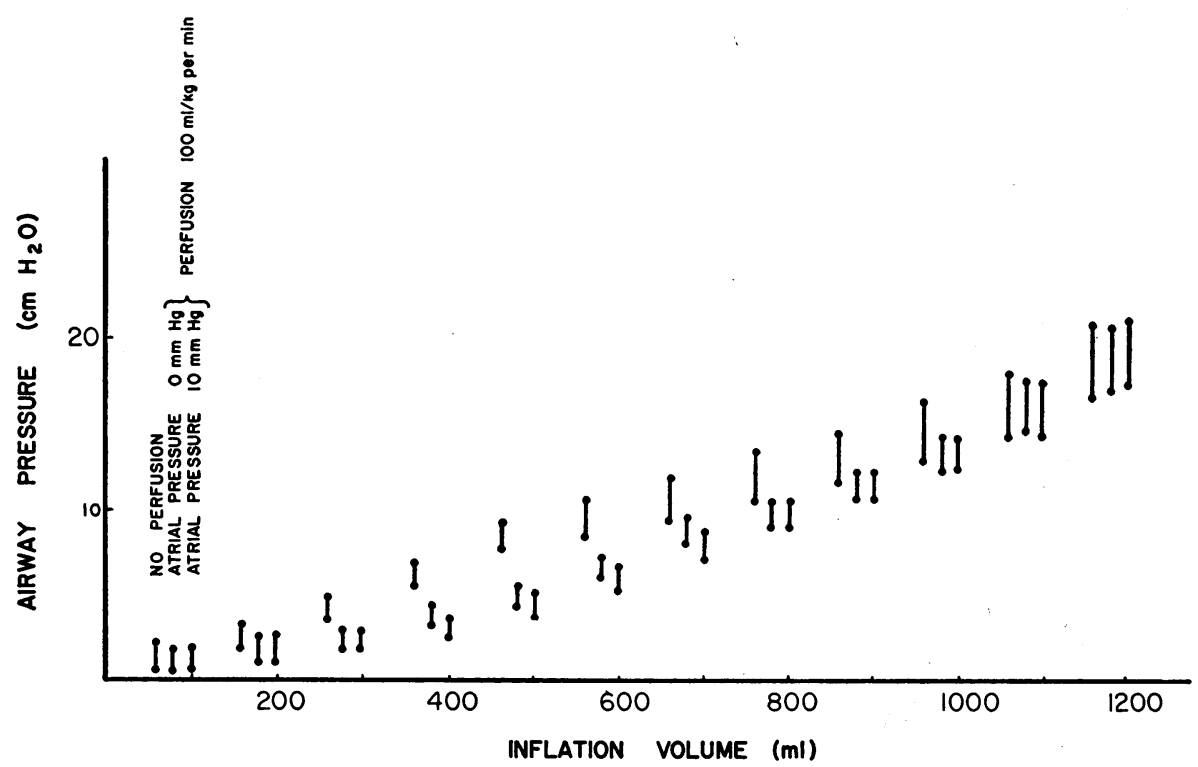

Fig. 5. EFFECT of Different venous PRESSURe. There was no significant difference between airway pressures when left atrial pressure was varied from 0 to $10 \mathrm{~mm} \mathrm{Hg}$. Blood flow was $100 \mathrm{ml} / \mathrm{kg}$ per min. Only the inflation data are plotted.

$200 \mathrm{ml} / \mathrm{kg}$ per min during the second, and 100 $\mathrm{ml} / \mathrm{kg}$ per min during the third. The data were similar for each flow rate. A slight progressive fall in compliance that was not related to the flow rate probably represented deterioration of the preparation.

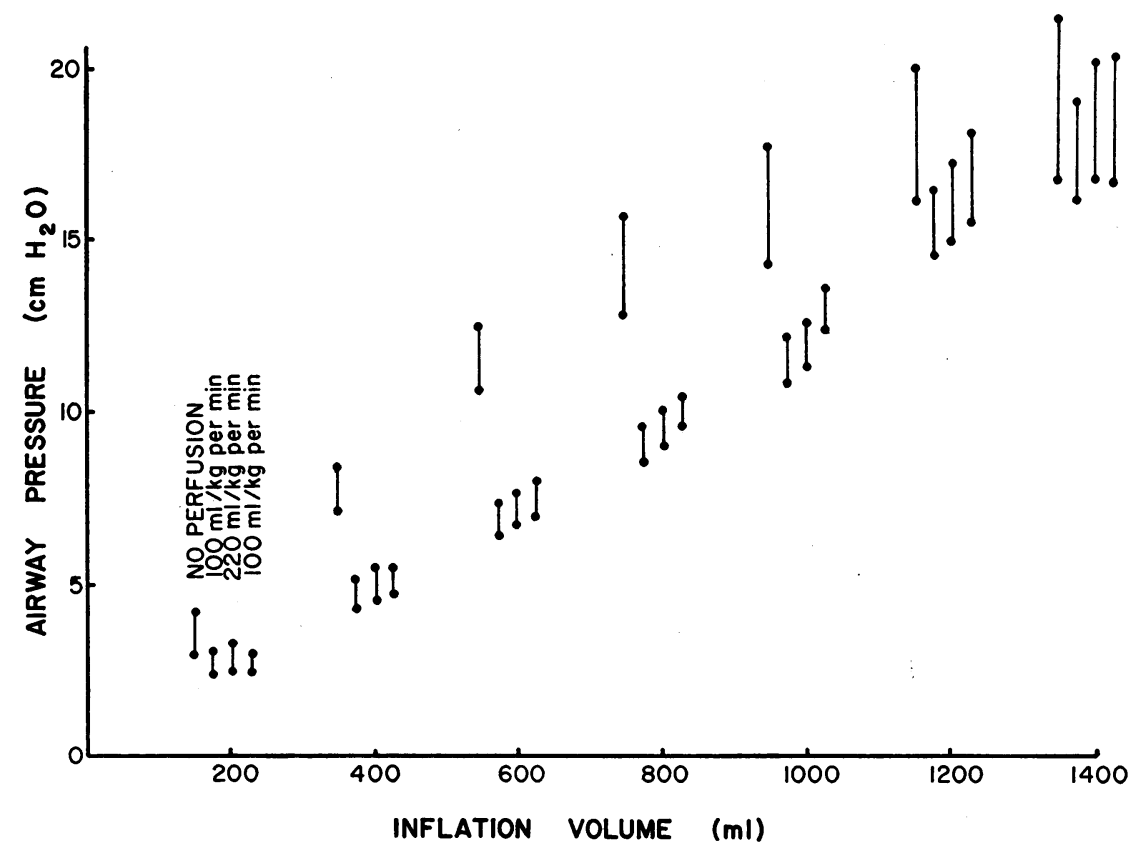

Fig. 6. EFFect of Different pUlmonary BLOOD Flow. Blood flow was alternated between 100 and $220 \mathrm{ml} / \mathrm{kg}$ per min. Left atrial pressure was $10 \mathrm{~mm} \mathrm{Hg}$. There is no significant difference in airway pressures. Only the inflation data are plotted. The slight, progressive rise in pressures probably is due to deterioration of the preparation. 


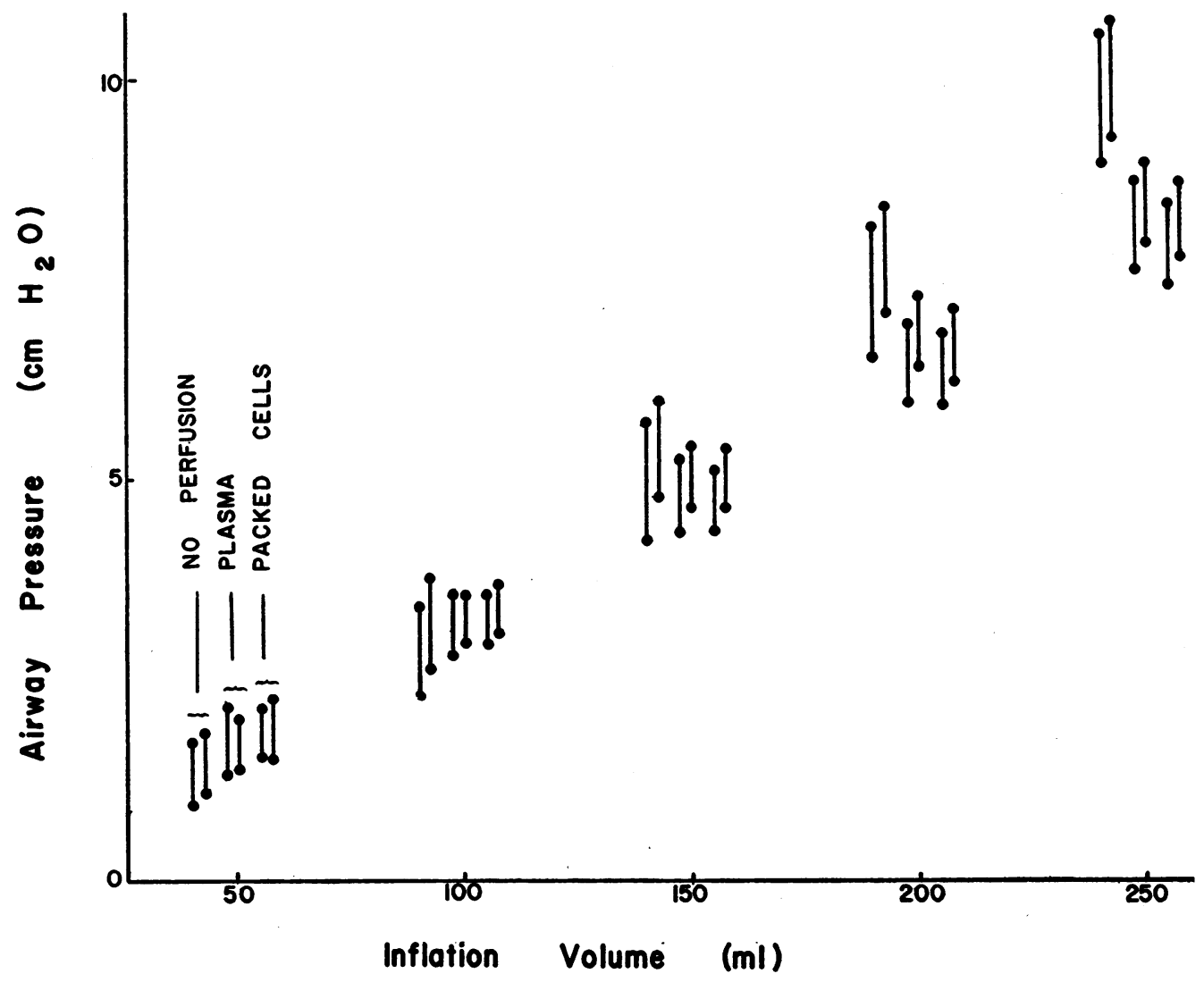

Fig. 7. EFfect of Different viscosity of perfusate. The inflation curves during inflation are plotted. Perfusion rate was $100 \mathrm{ml} / \mathrm{kg}$ per min. Left atrial pressure was $10 \mathrm{~mm} \mathrm{Hg}$. There is no difference between airway pressure with plasma and packed red cells (hematocrit $83 \%)$.

Perfusate viscosity did not seem to alter pulmonary mechanics. This aspect was very difficult to study because the preparation usually deteriorated before a comparison could be made between homologous plasma and packed red cell perfusates. Only one partially satisfactory set of data were obtained, shown in Fig. 7. Inflations were carried out only to a total volume of $250 \mathrm{ml}$, in $50-\mathrm{ml}$ increments so as to minimize the duration of the study. Perfusion rate was $100 \mathrm{ml} / \mathrm{kg}$ per min and left atrial pressure was $10 \mathrm{~mm} \mathrm{Hg}$. Airway pressures were similar with plasma and packed cell (hematocrit $83 \%$ ) perfusates and were lower than during the nonperfused state. We were unable to obtain satisfactory data to evaluate the effects of flow rate upon mechanics during perfusion with packed cells, because edema repeatedly occurred during the attempts.

During cyclic ventilation, dynamic compliance was significantly greater during vascular perfu- sion in the lower and the middle range of lung inflation, but there was no difference in the upper range of inflation. A $30 \mathrm{~kg}$ dog preparation was perfused at $100 \mathrm{ml} / \mathrm{kg}$ per min with left atrial pressure of $10 \mathrm{~mm} \mathrm{Hg}$ after data were first obtained without perfusion. The lungs were inflated with sequential $200-\mathrm{ml}$ increments of air to various volumes in the manner described heretofore in this paper. Then cyclic ventilation was begun. 300 $\mathrm{ml}$ of air was introduced and then withdrawn in a sine wave flow pattern after different levels of inflation volume were reached. Only $5-6 \mathrm{sec}$ was allowed between inflations, so that at the higher inflation volumes, stress relaxation was still occurring during the early phase of cyclic ventilation. Figs. $8 a, 8 b$, and $8 c$ show complete airway pressure tracings when cyclic ventilation was superimposed upon inflation volumes of 200,800 , and $2000 \mathrm{ml}$. Fig. $8 d$ graphically summarizes the data over the entire inflation range. 

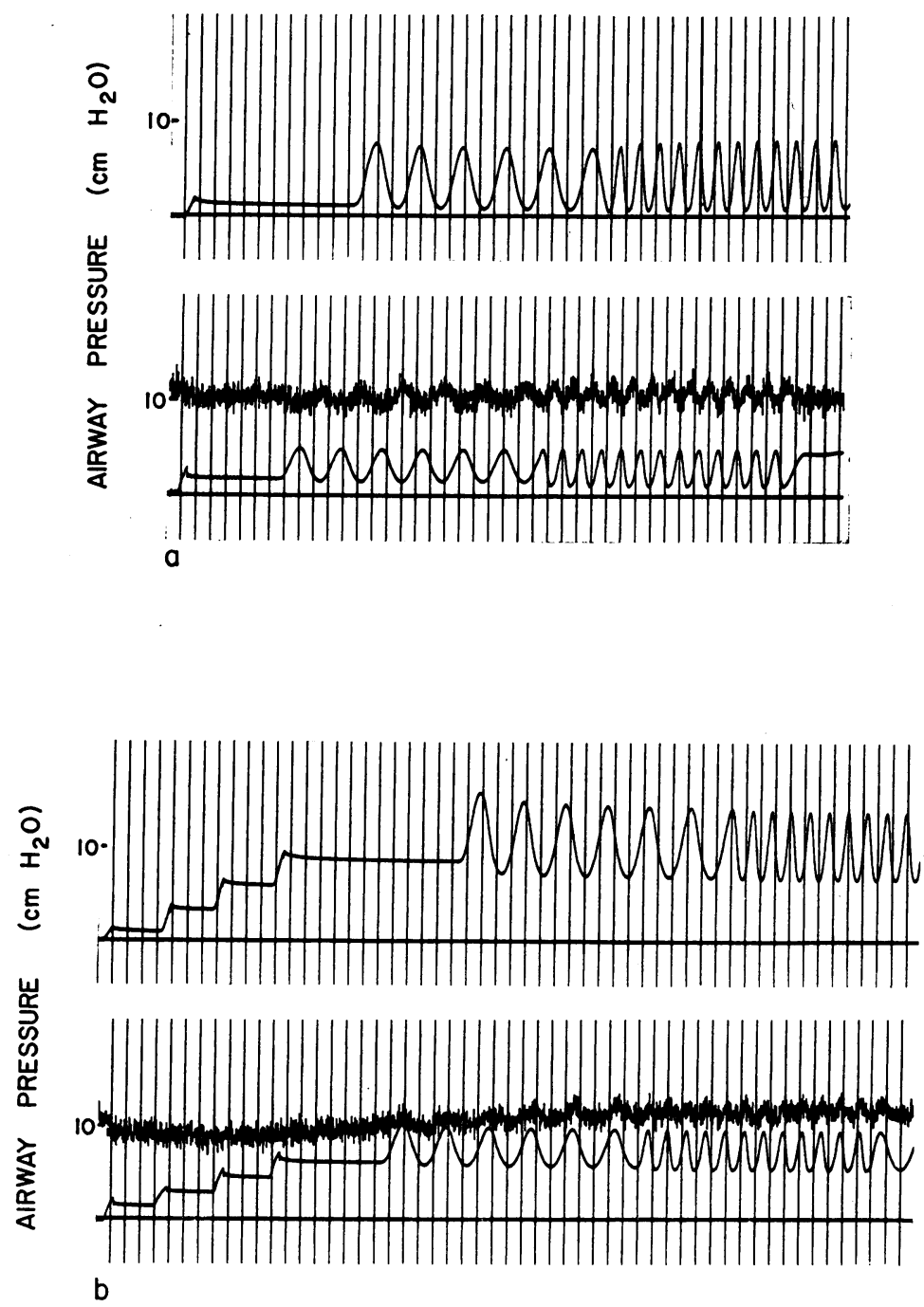

Fig. 8. EFFect of PUlmonary vascular Perfusion UPON DYNAMic COMPliance. Fig. $8 a$. 200 $\mathrm{ml}$ of air was introduced and then cyclic ventilations of $300 \mathrm{ml}$ were produced. The upper panel is without perfusion. The lower panel is with perfusion at $100 \mathrm{ml} / \mathrm{kg}$ per min. The left artial pressure was $10 \mathrm{~mm} \mathrm{Hg}$, which is the vascular pressure tracing. Figs. $8 b$ and $8 c$ are similar, except that the $300 \mathrm{ml}$ cyclic ventilations were superimposed upon 800 - and $2000-\mathrm{ml}$ inflation volumes of air, respectively. Fig. $8 d$ summarizes all the data from the study. The dots represent equilibrium pressures after the air had been introduced and before cyclic ventilation was started. The bars represent the airway pressure range during cyclic ventilation at these volumes. The time lines represent intervals of $1 \mathrm{sec}$. 

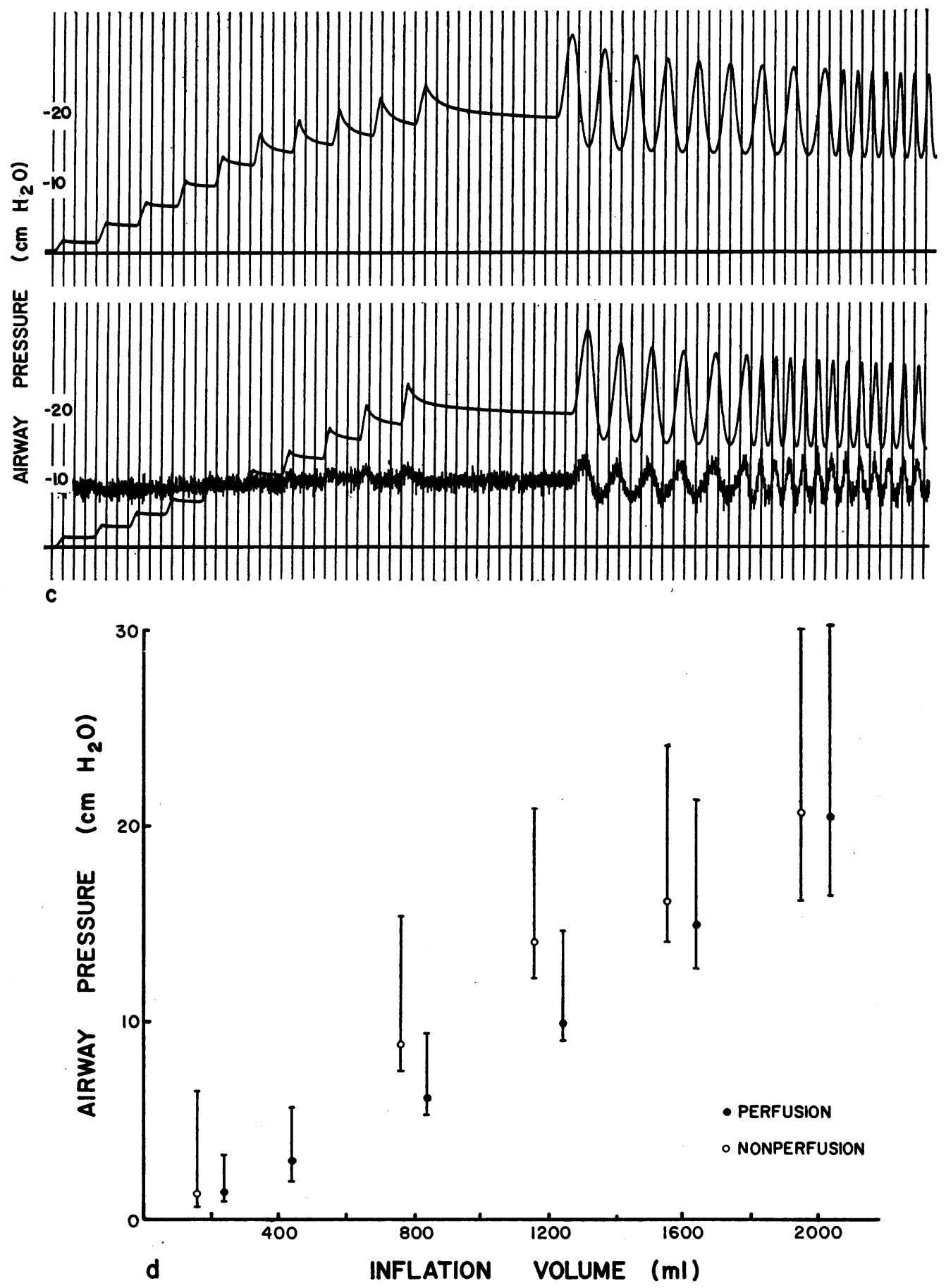

When perfusion was stopped and airway pressure measurements were made with static vascular distention, lung distensibility during inflation was always greater than in the nonperfused state. The relationship between vascular filling and lung distensibility was further studied in the two prepa- rations in which the vascular bed was statically distended from the graduated reservoirs.

Fig. 9 summarizes airway equilibrium pressures during inflation of one of these preparations; the results were similar in both. These data were from a $17 \mathrm{~kg}$ dog. The airway pressures during 


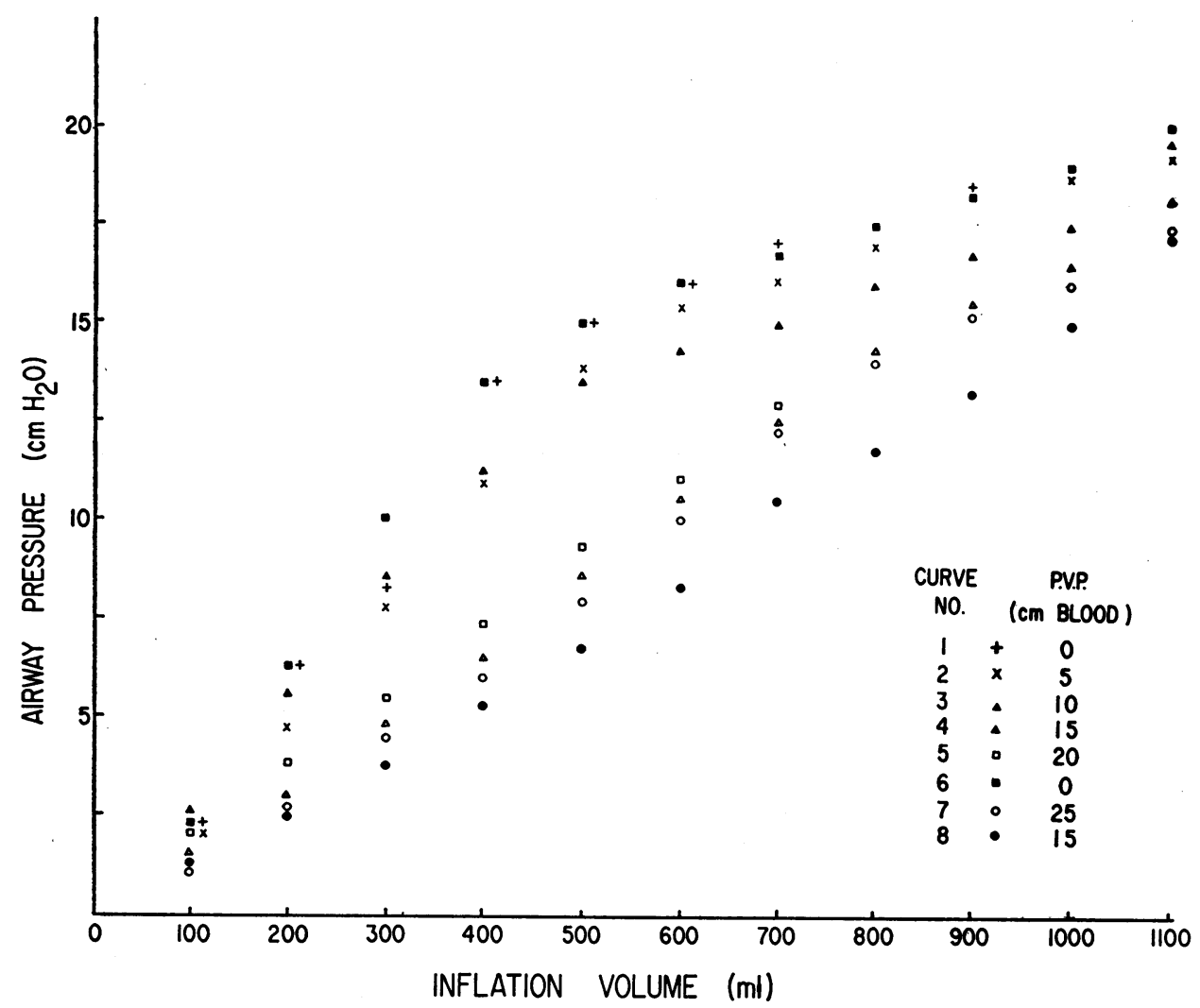

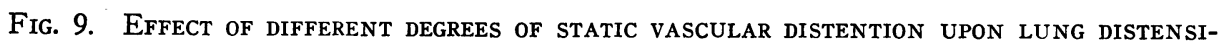
BILITY. Only the equilibrium airway pressures during inflation are plotted. There is significant improvement in lung distensibility up to a hydrostatic distending pressure of $15 \mathrm{~cm}$ blood, related to the midleft atrial level. Further vascular distention to $25 \mathrm{~cm}$ blood does not change lung distensibility. P.V.P., pulmonary vascular pressure.

deflation were similar with all degrees of vascular distention, and there was always hysteresis in the entire curve of inflation and deflation. Lung distensibility progressively improved during inflation as the vascular bed was increasingly distended up to a hydrostatic pressure of $15 \mathrm{~cm}$ of blood. Further distention to a pressure of $25 \mathrm{~cm}$ blood did

TABLE II

Lung blood volumes associated with vascular distending pressures

\begin{tabular}{|c|c|c|}
\hline Curve no. & Vascular pressure & Vascular vol \\
\hline \multicolumn{3}{|c|}{ cm blood } \\
\hline 1 & 0 & 10 \\
\hline 2 & 5 & 24 \\
\hline 3 & 10 & 50 \\
\hline 4 & 15 & 60 \\
\hline 5 & 20 & 118 \\
\hline 6 & 0 & 20 \\
\hline 7 & 25 & 133 \\
\hline 8 & 15 & 57 \\
\hline
\end{tabular}

not improve lung distensibility. Peak inflation airway pressures are not plotted, but they also decreased up to a distending pressure of $15 \mathrm{~cm}$ of blood. These various distending pressures were induced in a random sequence, so that the results were not related to time-dependent changes in the preparation. The sequence of vascular pressures, expressed as centimeters of blood, was $0,5,10$, $15,20,0,25$, and 15 .

A net loss of $30 \mathrm{ml}$ of blood into the preparation could not be recovered when negative pressure was placed upon the cannulae after these vascular pressures were measured. This loss presumably represented edema fluid which formed during the higher distending pressures, but which apparently did not affect lung distensibility. Table II gives the lung blood volumes associated with each vascular distending pressure. These volumes were determined before inflation. 


\section{Discussion}

Evaluation of the experimental methods. Deterioration of the preparation during the course of an experiment was manifested by two phenomena as described under results : edema formation, and progressive decrease in compliance. Edema formation was assumed to have occurred when the preparation gained weight under similar perfusion and inflation conditions. Generally, observations were continued if the total weight gain was under $60 \mathrm{~g}$. Since the order of observations was such that the pressures were first obtained without perfusion, when airway pressures generally were higher, edema formation would have lessened the observed differences between the nonperfused and the perfused lung. Similarly, the decrease in compliance that was not associated with weight gain also would have diminished the observed differences between the nonperfused and the perfused lung.

Air leaks were another problem but they probably did not change the qualitative nature of the results. The air leaks would be greater at the higher airway pressures, and since the airway pressures were always higher or the same in the nonperfused lung at all inflation volumes, the presence of a leak would have lessened rather than increased the difference in airway pressure between the nonperfused and perfused lung.

The presence of leaks made it impossible to control the total volume of the lung throughout an experiment. We assumed that the volume of gas in the lung was always the same at ambient pressure, after deflation from a maximal inflation. The virtual identity of repeated inflation-deflation curves under similar conditions suggested that lung volume at ambient pressure was constant. The pertinent question is whether the lung gas volume at ambient pressure was the same in the perfused as in the nonperfused lung. If there was a significant difference in this volume, then the differences of airway pressures between the perfused and the nonperfused lung might be related to a shift in the curve due to different lung gas volumes at ambient pressure. This possibility was disproved because the lung volumes measured by the closed-circuit method were similar with and without pulmonary vascular perfusion. Actually, volumes at ambient pressure were slightly greater with perfusion. There are several other reasons for believing that this mechanism did not significantly contribute to the difference in results between the perfused and the nonperfused states. Essential identity of pressures during deflation indicated there was no shift in the curve. Furthermore, variations in circulating blood volume, produced when left atrial pressure was altered, did not change airway pressures. Similarly, blood volume increased when pulmonary arterial pressure rose because of either the increased perfusion rate or the changeover from low viscosity, packed cell perfusates, and airway pressures did not change. Gas could not have been removed from the lung by the perfusate, which would thereby have caused lowered airway pressures, because the blood gas tensions had become equilibrated with room air before measurements were made. Furthermore, the deflation pressures would also have been lower, and all of the introduced gas would not have been recovered upon deflation.

The question may be raised concerning whether the data would have been similar with negative pressure inflation. The definitive answer can only be obtained by performing the experiment, but there are several reasons for believing that the results would be qualitatively similar with negative pressure inflation. The transpulmonary airway pressures are the same for a given degree of lung inflation with positive or negative pressure inflation, whereas there is a difference with respect to the relationship of airway to vascular pressure between the perfused and the nonperfused state. With negative pressure ventilation, the pressures in the distal airways are atmospheric at equilibrium and slightly less during inflow and slightly more than atmospheric during expiration. During positive pressure ventilation, airway pressure is positive, and for any given lung volume would be closer to vascular pressure than at the comparable volume with negative pressure ventilation. The similarity of airway pressures with different vascular pressures and flow rates suggests that the relationship of airway to vascular pressures is not a critical factor in this phenomenon, and that pulmonary vascular perfusion would have a similar effect upon the lung ventilated by negative transairway pressure.

Evaluation of the data. Pulmonary vascular perfusion had several effects: (a) less airway 
pressure was generated during active inflation in the middle range of inflation volumes; $(b)$ in this range the static equilibrium pressures were also less; $(c)$ at the upper range both pressures were similar in the perfused and nonperfused lung; $(d)$ pressures were similar during deflation with and without perfusion over the entire deflation range; (e) dynamic compliance was greater during perfusion in the middle range of inflation; $(f)$ there was no difference in dynamic compliance at the higher inflation volumes; and $(g)$ the higher pressures during active inflation were associated with increased stress relaxation. Qualitatively similar results were produced by static distention of the vascular bed. In the following discussion the term "perfused" will also designate the statically distended state, except where these two states are commented upon specifically.

It is reasonable to suppose that the molecular interactions that cause stress relaxation, whatever their nature, are initiated at the time the lung is set into motion, and, therefore, the forces of stress relaxation are not restricted to the interval after change in lung volume has stopped. This concept was confirmed qualitatively by the pressure tracings in the plethysmograph: when airway pressure could be shown to remain constant, or actually fall, while lung volume was increasing. Therefore, the conventional concept of the forces operating during lung inflation should be modified to include a "relaxing force," in addition to the forces of inertia, resistance, and elastance.

The changes between the perfused and the nonperfused lung must involve changes in these forces. Inertia, if altered at all, would be increased in the heavier, perfused lung and could not contribute to the observed changes. A decreased resistance could have contributed to the decreased pressure build-up during active inflation, but would not explain the difference in static equilibrium pressures. Any decrease in resistance would have occurred in the smaller terminal airways, where vascular filling could alter airway diameters.

The elastic behavior of the lung is due to two components: one related to the elastic properties of the lung itself, and one related to the number of terminal units participating in inflation at a given lung volume. The elastic properties of the lung itself are due in turn to two factors: the properties of the parenchyma, and those of the alveolar surface-lining material. Pulmonary vascular perfusion should not have altered the inherent elastic properties of lung parenchyma, and the fact that static compliance was similar at the upper limit of inflation and throughout deflation indicates that they were unchanged by perfusion. Similarly, the viscoelastic properties of the lung parenchyma, related to stress relaxation, should not have been altered by perfusion.

Alterations in surfactant probably did not play a role in the observed results. The effects of surfactant can be shown by comparing static fluidand gas-filled lungs, which differ in mechanical behavior in three striking ways (10). Firstly, there is virtual absence of hysteresis in the fluidfilled lung, so that the inflation and deflation pressure-volume curves are almost identical. Secondly, over-all distensibility is improved in the fluid-filled lungs so that for each volume during deflation, airway pressure is significantly less. Thirdly, inflation of the atelectatic lung proceeds irregularly with air yet very smoothly with fluid. Although we observed less hysteresis in the perfused than in the nonperfused lung, the pressures during deflation were identical, which is not in agreement with the second of the above conditions. The readily reproducible nature of the data when the lungs were alternately inflated with and without perfusion indicates there was no deterioration of surfactant during the course of an experiment.

The uniform nature of fluid lung inflation suggests that surface forces in the gas-filled lung cause irregular opening of airway units. Having considered in the above discussion other causes of improved distensibility during inflation, the only remaining reasonable explanation is that pulmonary vascular distention increased the number of terminal respiratory units contributing to lung inflation at any given total lung gas volume, and that these units also opened more readily. At the upper range of lung inflation, where pressures were similar, the same number of units probably were opened, with and without vascular distention. During deflation the sequence of emptying was then similar under both conditions.

Vascular distention could play a direct or an indirect role in facilitating airway opening. The distended vessels might have a direct scaffolding effect around terminal airway orifices. This seems the likely explanation. Conceivably, vascular dis- 
tention could alter the configuration of surfactant at the airway openings, but this possibility appears to be more remote. The surface tension of surfactant decreases as its thickness increases, and when the surfactant surface is stretched, the surface tension increases. Therefore, vascular distention would have to thicken the surfactant layer at the airway orifices in order to lower surface tension and facilitate airway opening by this mechanism. Instead, the collapsed orifice would be expected to have a thicker surfactant layer than the opened orifice. It is actually reasonable to suppose that the opening effect of the vascular scaffolding around the orifices of terminal airways is opposed, not facilitated, by surface tension if the latter increases as the orifice assumes a more circular shape.

Distension of the vascular bed per se improved pulmonary mechanics. Active blood flow is not required and perfusate viscosity probably does not matter. Vascular bed distention would be able to affect airway diameter only beyond the level of cartilaginous support. Staub has published photographs taken from the work of Nadel, Olsen, and Colebach (11). The latter authors showed that pulmonary microembolization caused alveolar duct collapse. There may also have been more proximal airway collapse. The vascular distention affecting compliance must occur in the pulmonary microcirculation associated with these terminal airways. In our study it is not possible to relate the total lung blood volume changes to volume changes in the small vessels. In the static distention preparations, the variations in blood volume were distributed throughout the cardiac chambers and the entire vasculature.

A valid correlation can be made, however, between pressure in the small vessels and lung distensibility. With static distention, all of the vessels, irrespective of size, at a given height relative to the reservoir surfaces were subjected to the same hydrostatic distending pressure. Above a hydrostatic pressure of $15 \mathrm{~cm}$ blood, related to mid-left atrium, no further improvement of compliance occurred; the dorsal regions of the lung were subjected to about $10 \mathrm{~cm}$ pressure and the ventral regions to about $20 \mathrm{~cm}$.

The data from Fig. 5 show that in the lung perfused at $100 \mathrm{ml} / \mathrm{min}$ per $\mathrm{kg}$ of dog weight, distensibility was improved to the same extent when atrial pressure was 0 and $10 \mathrm{~mm} \mathrm{Hg}$, and mean pulmonary arterial pressure was 28 and $32 \mathrm{~mm}$ $\mathrm{Hg}$, respectively. There must have been optimum distention in both cases of those small vessels responsible for improved compliance. The data from the static distention studies would suggest that this was at least approximately $15 \mathrm{~mm} \mathrm{Hg}$.

From this study it is not possible to present a precise description of the capillary distending pressures in an intact subject relative to lung compliance. However, these data suggest that the optimal distending pressure is in the range of normal pulmonary capillary pressure. Acute distention up to a hydrostatic column, $25 \mathrm{~cm}$ of blood, did not cause either further increase or a decrease in compliance. This is in accord with Bondurant's findings that acute pulmonary congestion in normal humans, induced by inflation of an antigravity suit, did not change pulmonary compliance (12).

It is difficult to relate the results from our study to information in the literature concerning the effects of altered pulmonary vascular perfusion upon lung mechanics in abnormal clinical and experimental situations. Usually there are associated lung parenchymal or metabolic changes, so that measured differences in mechanics cannot be related solely to vascular change.

Our study also suggests that lung ventilation is characterized by a relaxing force which is present while lung volume is increasing. This force is made up of two components : the viscoelastic properties of the lung and the sequential opening of terminal respiratory units by redistribution of gas already in the lung. Pulmonary vascular perfusion facilitates this latter component, namely relistribution of lung gas.

\section{References}

1. Basch, S. 1887. Ueber eine function des capillardruckes in den lungenalveolen. Wien. Med. Blatter. $10: 465$.

2. Cook, C. D., J. Mead, G. L. Schreiner, N. R. Frank, and J. M. Craig. 1959. Pulmonary mechanics during induced pulmonary edema in anesthetized dogs. J. Appl. Physiol. 14 : 177.

3. Frank, N. R., H. A. Lyons, A. A. Siebens, and T. F. Nealon. 1957. Pulmonary compliance in patients with cardiac disease. Am. J. Med. 22: 516.

4. Lewin, R. J., C. E. Cross, P. A. Rieben, and P. F. Salisbury. 1960. Influence of decreased vascular 
pressures on mechanics of ventilation in dogs. Am. J. Physiol. 198 : 873.

5. Borst, H. G., E. Berglund, J. L. Whittenberger, J. Mead, M. McGregor, and C. Collier. 1957. The effect of pulmonary vascular pressures on the mechanical properties of the lungs of anesthetized dogs. J. Clin. Invest. 36: 1708.

6. Ayres, S., R. Kozam, and D. Lukas. 1960. Mechanics and work of breathing in atrial septal defect. Circulation. 22 : 718.

7. Frank, N. R. 1959. Influence of acute pulmonary vascular congestion on recoiling force of excised cats' lung. J. Appl. Physiol. 14: 905.

8. Donald, D. E. 1959. A method for perfusion of isolated dog lungs. J. Appl. Physiol. 14: 1053.
9. Donald, D. E., and D. Ferguson. 1962. Pulmonary vascular resistance and duration of perfusion in isolated lung of dog. J. Appl. Physiol. 17: 159.

10. Radford, E. P., Jr. 1964. Elasticity of Lungs. In Handbook of Physiology. W. O. Fenn and $\mathrm{H}$. Rahn, editors. American Physiology Society, Washington. 1 : 433.

11. Staub, N. C. 1963. The interdependence of pulmonary structure and function. Anesthesiology. 24: 831 .

12. Bondurant, S., J. Mead, C. D. Cook. 1960. A reevaluation of effects of acute central congestion on pulmonary compliance in normal subjects. J. Appl. Physiol. 15 : 875. 